$51 \mid$ InterAção

\title{
A INTEGRAÇÃO REGIONAL NOS GOVERNOS SARNEY E COLLOR: UMA MUDANÇA DE \\ PARADIGMAS
}

REGIONAL INTEGRATION IN SARNEY AND COLLOR ADMINISTRATIONS: A PARADIGM SHIFT

Marcos Pascotto Palermo ${ }^{1}$

Reginaldo Teixeira Perez ${ }^{2}$

\section{Resumo}

Trata-se, neste paper, do processo de integração regional no Cone Sul. Em especial, analisam-se os reflexos da mudança de perspectiva ideológica adotada pelo Estado brasileiro - a saber, da desenvolvimentista à liberal - nos governos Sarney e Collor. O questionamento a instar a reflexão diz respeito a uma possível alteração de perspectiva integracionista em face da metamorfose experimentada pelo Estado brasileiro - antes no desenvolvimentismo, após no liberalismo. Com o emprego de salientes traços do método histórico, além da literatura afeita ao tema, mobilizam-se conceitos e suas respectivas definições para fins de esclarecimento deste momento crucial dos processos de (re)democratização desta quadra da América Latina.

Palavras-chaves: Integração Regional, Governos Sarney e Collor, Desenvolvimentismo, Liberalismo.

\begin{abstract}
This paper treats of the integration process in the Southern Cone. In particular, we analyze the effects of the changing ideological perspective adopted by the Brazilian government - namely, from developmental one, to liberal one - in the Sarney and Collor administrations. The questioning claims the reflection with respect to a possible change of integrationist perspective in relation to the metamorphosis experienced by the

\footnotetext{
${ }^{1}$ Mestre em Ciências Sociais pela Universidade Federal de Santa Maria (UFSM). Professor Assistente do Centro Universitário Franciscano (UNIFRA) e licenciado da Faculdade de Santa Maria (FADISMA). E-mail: marcosppalermo@yahoo.com.br

2 Doutor em Ciência Política (Ciência Política e Sociologia) pela Universidade Candido Mendes / Instituto Universitário de Pesquisas (UCAM/IUPERJ). Professor Titular do Departamento de Ciências Sociais e do PPGCS da UFSM. E-mail: rtpp10@hotmail.com
} 
52 InterAção

Brazilian government - before developmentalism one, after liberalism one. With the use of salient features of the historical method and regular literature connected to the theme, concepts and their definitions are mobilized for clarity of these crucial moments of the processes of (re)democratization of this part of Latin America.

Keywords: Regional Integration, Sarney and Collor Administrations, Developmentalism, Liberalism.

\section{INTRODUÇÃO}

O presente artigo disserta sobre a atuação dos governos dos presidentes José Sarney (1985-1990) e Fernando Collor (1990-1992), no que se refere à integração regional no lapso de tempo que corresponde ao fim do período da política externa do Estado Desenvolvimentista e em que surgem as tentativas de reforma do Estado, levadas à execução, primeiramente, pela concepção liberal de Collor e desenvolvidas, ainda que em parte, por governos posteriores.

Em sentido lato, o Estado Brasileiro vem tentando atuar, num sentido integracionista de diferentes matizes, perspectivas e ambições em um tempo considerável. $\mathrm{O}$ experimento que resultou na construção de uma organização internacional regional mais significativa, o Mercosul, nasceu nesta época com a redemocratização política, após períodos autoritários, tendo prosseguimento em um período histórico de diferente concepção acerca do Estado e do que se definia por autonomia. Conjuntamente, a realidade mundial experimentava os ares de um fenômeno de globalização liberal mais acentuado.

O trabalho, ora apresentado, visa a contribuir para a análise das atuações políticas dos governos citados, tomando-as como formadoras de integração regional neste contexto. Trata ainda, sem uma análise mais aprofundada, da situação política de outros Estados, em especial a Argentina. 
Em um primeiro momento, vê-se que o Governo Sarney, foi em boa medida o herdeiro de um modelo de Estado Desenvolvimentista, que projetou o crescimento econômico brasileiro, com diferentes vieses, desde a Era Vargas e que entrara em decadência no início da década de 1980, perigeu dos governos militares, com consequências para a política externa.

Na sequência do governo Sarney, após a redemocratização, vê-se com Collor a emergência do que viria a ser um arranjo neoliberal ${ }^{3}$ na condução governamental do Estado. Assim, Collor seria, no Brasil, o primeiro presidente a ser identificado com políticas contemporâneas liberalizantes e a sua atuação como líder novel poderia ter causado dúvidas quanto à identidade de uma pretensão de integração regional no âmbito externo. Diz-se que ele é influenciado por aquilo que passaria à história como Consenso de Washington ${ }^{4}$.

\footnotetext{
3 A definição de neoliberal gerou controvérsia conceitual e principalmente contestação. Redundou em discursos negativos ou positivos, conforme a defesa ou negação da sua implementação, tanto na política interna quanto na política externa. 0 aparecimento do neoliberalismo é tido como fruto da retomada conceitual e crítica de pressupostos liberais do início do século XX. Dá-se em um contexto de oposição às ideias de John Maynard Keynes que viriam influenciar a participação/intervenção estatal na economia, como meio da promoção do bem-estar social, num modelo de Estado que ficou conhecido pela expressão inglesa Welfare State. 0 Estado de Bem-Estar Social teria defensores de distintos matizes conforme a sua execução em diferentes países, mas conheceria os seus rivais analíticos nos pensadores que aderiram ao neoliberalismo. Reis da Silva (2009) sintetiza o processo de construção histórica neoliberal, a partir das análises de Perry Anderson. Toma-se a obra "A caminho da Servidão", do economista austríaco Friedrich Hayek, como a influenciadora das propostas neoliberais a partir de sua publicação em 1944. Em 1947, a convite de Hayek, tem início na localidade suíça de Mont Pélerin as reuniões de uma sociedade que seria batizada com mesmo nome e que congregaria pensadores como Milton Friedman, Karl Popper, Ludwig Von Mises, entre outros. Da proposição de ideias à assunção das mesmas como práticas de governo com vistas à adequação estatal, transcorreram mais de trinta anos, até as vitórias eleitorais de Margareth Thatcher na Grã-Bretanha (1979), Ronald Reagan nos Estados Unidos (1980) e Helmut Kohl na então Alemanha Ocidental (1982). 0 mesmo Reis da Silva, ainda situa governos de centro-esquerda, como o de Felipe González na Espanha (1982-1996), como uma versão do neoliberalismo.
}

\footnotetext{
${ }^{4}$ Refere-se ao conjunto de medidas econômicas traçado na capital norte-americana em fins de 1989, em especial oriundas do receituário macroeconômico do britânico John Williamson, ${ }^{4}$ com apreço de organismos internacionais como o Fundo Monetário Internacional, o Banco Mundial e o Banco Interamericano de Desenvolvimento. Silva e Gonçalves (2005) traduzem os pontos acordados no "consenso" nos dez itens a seguir: I - eliminação dos déficits públicos por meio de rigorosas disciplinas fiscais; II - criteriosa priorização dos gastos públicos; III - reforma tributária para a desoneração dos setores produtivos; IV - abertura do mercado financeiro; V - flexibilização do regime cambial com base na referência externa (ou seja, o câmbio de mercado); VI - abertura do mercado às exportações; VII captação do capital estrangeiro para financiamentos diretos; VIII - privatização de empresas estatais; IX desregulamentação da economia; $X$ - adoção de critérios de proteção da propriedade intelectual.
} 
$54 \mid$ InterAção

A hipótese defendida neste trabalho é de que se torna possível observar uma transição de paradigmas, a partir das descrições históricas das políticas governamentais. Assim, o artigo terá o seu início no momento imediatamente anterior ao governo Sarney e passará em seguida ao governo Collor, com a descrição da atuação governamental no sentido da integração regional.

\section{A INTEGRAÇÃO REGIONAL DA DÉCADA DE 1980: DO OCASO DO REGIME MILITAR À ELEIÇÃO DE TANCREDO NEVES}

Para centrar-se na análise da integração regional da década de 1980, é imperioso ter em mente que se tem, no Brasil, o Estado com viés desenvolvimentista e que o grande impulsionador integracionista será o Governo Sarney.

Antes disso, porém, no governo de João Figueiredo (1979-1980), o Estado brasileiro assiste à uma situação econômica sem chances de crescimento. Moniz Bandeira (2003) explica que a dívida externa eclodira no início da década de 1980 e podia se concluir que a situação social havia se deteriorado, sem que a riqueza produzida pelas políticas econômicas de governos anteriores pudesse ser distribuída de forma minimamente equânime entre a população. Com isso, abriram-se campos para a possibilidade de se repensar perspectivas na condução da política do Estado brasileiro. Estas vieram acopladas como foi dito, em um contexto histórico posterior, como favoráveis à liberalização da economia. Refletiriam, portanto, nas possibilidades de se negociar a integração.

Há uma distensão das relações com a Argentina, e o Acordo Tripartite entre Brasil, Paraguai e Argentina, que pôs fim à questão de Itaipu foi assinado 
em 19 de outubro de 1979. Pereira (2003) salienta, nesse contexto, a aproximação dos três países, fato impensável em momentos anteriores.

Digna de nota é ainda neste governo a ocorrência da Guerra das Malvinas. O conflito deu-se entre a Grã-Bretanha e a República Argentina, devido à reivindicação da soberania argentina pelo território insular, chamado pelos britânicos de Falkland. Em 1982 a crise chegou às vias de fato e propiciou a derrubada da ditadura militar argentina. Em 1983, na cidade paranaense de Foz do Iguaçu, Figueiredo e o então presidente argentino general Reynaldo Bigone, assinam em 13 de janeiro, um contrato para a interconexão dos sistemas de energia elétrica de Argentina e Brasil, bem como é lançada a pedra da ponte ${ }^{5}$ que ligaria os dois países.

As condições externas sentidas pelo governo de Sarney no plano extraregional já estavam desenhadas.

No âmbito latino-americano, finda a atividade da Associação LatinoAmericana de Livre-Comércio (ALALC), surge a Associação Latino-Americana de Integração e Desenvolvimento (ALADI) com novas perspectivas, o que vale relembrar. Saba (2002) explica que esta última organização abandonou os padrões rígidos de prazos dados para a integração latino-americana que haviam sido previstos pela ALALC. Desses, passa-se a uma flexibilização que previa a possibilidade de ajustes bilaterais na conformação de uma área de preferências. Continua a referência teleológica da antecessora, a de estabelecimento de um mercado comum latino-americano, construído em longo prazo e de forma gradual e progressiva, assim como prevê o seu tratado constituinte. Estabelecese a possibilidade da celebração de acordos parciais sub-regionais, que depois estariam abertos ao multilateralismo. Ou seja, poderiam ser realizados acordos

\footnotetext{
${ }^{5} 0$ gesto simbólico ali esboçado, bem como o aproveitamento deste por governos posteriores, será explanado a seguir.
} 
56 InterAção

que não envolvessem todos os membros da associação, desde que posteriormente fosse possibilitada a adesão dos demais. Era a implicância do princípio da convergência, garantidor de um aprofundamento da integração regional.

No âmbito interno, tal como já preconizado pelo regime, a transição para a democracia se dá de forma lenta e gradual sob o controle das elites políticas dirigentes, explica Pereira (2003).

A política externa dos governos civis que sucedessem aos governos militares não poderia fugir, neste ínterim, do quadro de transição apresentado: o de uma abertura democrática gradual (e controlada). Hirst (1985), ao analisar o quadro da redemocratização em conjunto com a atuação exterior do Brasil, salientava o programa do maior partido de oposição ao governo militar, o Partido do Movimento Democrático Brasileiro (PMDB), no que tange à política externa. O PMDB que lançara, ainda na campanha eleitoral de 1982, um documento partidário com várias propostas do partido, dava sinais de que o seu pensamento em pouco diferia da estruturação da política externa traçada, pelo menos no que tange ao último governo militar. Anexava de significativo, segundo a autora, apenas a normalização das relações com Cuba, no contexto latino-americano, associado à preocupação enfática com a autodeterminação dos povos e a democracia, na qual se condenava as práticas de desestabilização e interferência externa.

O PMDB chega ao poder em conjunto com a Frente Liberal, dissidência dos apoiadores do regime militar, e viria a eleger o sucessor civil do regime. A redemocratização oferece ao Brasil um episódio traumático: a morte do primeiro civil eleito presidente. Tancredo Neves, ainda que eleito indiretamente, representava simbólica e faticamente o fim de mais de vinte anos de governos militares. Ao falecer, ele deixa um ministério nomeado, o que incluía o Ministro das Relações Exteriores, Olavo Setúbal. O novo chanceler, como recorda Danese 
$57 \mid$ InterAção

(1999), permaneceria por um ano à frente do Itamaraty, até a indicação do chanceler Abreu Sodré, que viria a conservar-se maior tempo à frente do cargo.

Tancredo, em sua rápida incursão como presidente eleito, viria a fazer de forma também célere, aquilo que é chamado de diplomacia presidencial. Segundo Danese (1988), em seu "momento presidencial", o presidente eleito realiza uma maratona de viagens. Na América Latina, houve a passagem pelo Peru, México e Argentina.

\section{GOVERNO SARNEY6}

José Sarney, o vice e sucessor de Tancredo na presidência do Brasil, defrontou-se com um período de crise econômica e com a obrigação de dar uma resposta a litígios comerciais internacionais. A respeito disso, Pereira (2003) mostra que esta necessidade fazia com que a política externa precisasse conciliar, neste momento, perspectivas desenvolvimentistas de cunho nacionalista, com a necessidade de apoio do exterior7. Em uma conjuntura de negociação comercial desfavorável, não só para si, como para demais países da América Latina, a opção seria a da aproximação com os países fronteiriços, em especial com os do Cone Sul e neste caso a Argentina.

Quanto à Argentina, lembra Ayerbe (1998), que em 1985 a situação econômica piora vendo-se o fracasso do Plano Austral. Isso impossibilita uma

\footnotetext{
${ }^{6}$ Sobre a bibliografia usada neste ponto do artigo, vale sinalizar que quando se refere aos relatórios e resenhas do Ministério das Relações Exteriores, a citação deve ser lida com cuidado para evitar confusão. Geralmente tais dados são publicados em momentos posteriores aos anos analisados, devendo o leitor ter em mente, que se procurou um viés cronológico para a feitura deste trabalho, priorizando uma sequência anual quando possível. A opção se justifica para mostrar avanços e entraves no processo de integração, as estratégias e mudanças de perspectivas do enfoque dado pelo Estado brasileiro.

${ }^{7}$ Que poderiam ver-se incluídas, ainda que paradoxalmente, na mesma urgência de contornar a crise econômica vivida, com a possibilidade de garantir desenvolvimento econômico.
} 
retomada do controle da economia por parte do Estado argentino e gera preocupação com pactos sociais firmados. As dificuldades argentinas parecem mostrar que o país estava encurralado entre enfrentar o receio de que seus produtos não fossem tão competitivos quanto os brasileiros e a ausência de melhor perspectiva.

A Argentina, porém, não tinha outra opção, nem econômica nem política. Os EUA, com produção agropastoril similar à sua, nunca propiciaram um bom mercado para as suas exportações. A Grã-Bretanha, por sua vez, integrara a CEE, que passou a competir no mercado mundial de carne e cereais, oferecendo estes produtos a preços subsidiados. E a Guerra das Malvinas provocara o dissenso político tanto com a CEE quanto com os EUA, em virtude da ativa solidariedade que deram à GrãBretanha. Só restava à Argentina, por conseguinte, o caminho da associação com o Brasil (MONIZ BANDEIRA, 2003, p. 467).

Em 1985 o relatório anual do Ministério das Relações Exteriores ${ }^{8}$, abria a sua edição com a seguinte colocação

Área prioritária da atuação externa do Brasil, as relações com os países americanos tiveram importantes desdobramentos em 1985. Nesse contexto, a América Latina e, em especial, a América do Sul construíram-se no ponto de atenção principal do esforço diplomático brasileiro (BRASIL, 1986, p.07).

Sarney inicia esta atuação estatal de forma marcante. Se situarmos um marco histórico-legal, este está em 29 e 30 de novembro de 1985, quando da inauguração da já citada ponte que passara a ligar a cidade brasileira de Foz do Iguaçuª Puerto Iguazú na Argentina.

\footnotetext{
8 Relatório que dava conta do ano de 1985, mas publicado em 1986.

9 No texto da Declaração de Iguaçu, coloca-se como ligação entre a cidade brasileira de Porto Meira e Puerto Iguazú a localização da ponte. Na verdade, Porto Meira é o bairro da cidade de Foz do Iguaçu onde está localizada a mesma.
} 
59 InterAção

Por um lado, revela-se que a linguagem mudava, sendo que o universo simbólico $^{10}$ é explorado mais uma vez. Segundo Galvão Flores (2005), as iniciativas de "construção de pontes", como a que na ocasião fora construída, significa a aproximação. De outra parte, significa concretização, já que a mesma era prevista desde os governos militares. A Ponte Internacional da Fraternidade trazia consigo o nome de Ponte Tancredo Neves, o que, na visão corroborada pela autora, era uma ironia. Tancredo, ao chegar de sua viagem a Washington, percebeu, em fevereiro daquele ano, que na condição de presidente eleito não poderia radicalizar com relação à negociação da dívida externa. Amarrado a esta preocupação, não fizera nenhuma proposta concreta de aproximação ao presidente argentino Raúl Alfonsín, o que frustrara o mesmo, na opinião de cientistas políticos que observavam a situação ${ }^{11}$.

De prático uma série de acordos cooperativos é estabelecida. Na área de energia nuclear, a Declaração Conjunta sobre Política Nuclear, que consubstanciava os propósitos pacíficos dos programas de desenvolvimento dos dois países no campo nuclear. Na cooperação econômica, a Ata de Iguaçu, também chamada de Declaração de Iguaçu, que previa a integração econômica entre os dois países.

Na mesma Declaração, eram dadas as previsões de cooperação no âmbito energético, e externaram-se preocupações com a situação de crise econômica enfrentada. Foi citado o Consenso de Cartagena de 1984, revelando a percepção latino-americana sobre a mesma. O Atlântico Sul, na visão expressa, deveria ser área desmilitarizada, zona de paz e cooperação, longe do conflito leste-oeste ${ }^{12}$. Ainda citaram a crise centro-americana e a importância do Grupo de Contadora

\footnotetext{
${ }_{10}$ Ao se referir a simbólico, pode-se remeter às dimensões do agir humano, citadas por Bobbio (1998) como necessárias à compreensão da Ciência Política.

11 É o caso de Mônica Hirst, na informação trazida por Galvão Flores (2005).

12 Referia-se à Guerra Fria.
} 
$60 \mid$ InterAção

na sua resolução. Também exteriorizava o reconhecimento do Presidente Alfonsín, pela solidariedade brasileira na questão das Malvinas.

Além disso, era retomada a dimensão simbólica, as fronteiras (antes tidas como de separação), eram neste universo de palavras e medidas políticas, preparadas para a ação estatal como instrumento de cooperação, parte da atuação governamental e da burocracia diplomática, ao sabor da necessidade dos Estados.

O passo seguinte vem na visita de Sarney à cidade de Buenos Aires de 28 a 30 de julho de 1986, com a assinatura da Ata para a Integração BrasilArgentina $^{13}$. Pereira (2003) salienta que se estabelece um programa de cooperação na economia, composto de doze protocolos. Estes versavam, principalmente, sobre bens de capital e estabeleciam que houvesse o favorecimento de condições preferenciais no intercâmbio bilateral entre os dois países frente a terceiros. Foi negociada uma lista comum de produtos a receberem estas condições. A importação de trigo argentino pelo Brasil foi acertada, bem como a cooperação de produtos alimentícios.

A respeito disso, salienta ainda Galvão Flores (2005) que este foi o ponto de partida para a feitura jurídica do Programa de Integração e Cooperação Econômica (PICE), que viria a gerar 24 protocolos setoriais nos anos restantes do governo de Sarney. Segue-se a assinatura da Ata de Amizade ArgentinoBrasileira, Democracia, Paz e Desenvolvimento, datada de 10 de dezembro de 1986.

Somam-se às questões relativas aos produtos agrícolas, em especial o trigo, aquilo que o Itamaraty define no mesmo relatório como áreas prioritárias para o

13 Refere-se aqui à Ata para Integração e Cooperação Econômica. 
$61 \mid$ InterAção

Programa de Integração: os bens de capital, comércio, as empresas binacionais ${ }^{14}$, de investimentos, energia, serviços, tecnologia de ponta, assuntos nucleares, transportes, comunicações e siderurgia.

Ainda de acordo com o Ministério das Relações Exteriores, em seu relatório anual de 1986, editado em data posterior ${ }^{15}$, quanto à questão das ilhas Malvinas existiram posicionamentos significativos. Após incidentes envolvendo navios pesqueiros argentinos e aviões militares britânicos, houve queixas formais apresentadas na ONU e na OEA feitas pela Argentina. Relacionado a este problema está a criação, por parte da Grã-Bretanha, em 29 de outubro de 1986, de uma zona para conservação de pesca, relatada em outros pontos deste documento oficial como zona de exclusão. Na sua dimensão de duzentas milhas se superpunha à zona econômica exclusiva sob jurisdição argentina. ${ }^{16}$

Revelando ação de uma solidariedade imediata, teve lugar uma reunião, em 02 de novembro de 1986, na cidade uruguaia de Punta del Este, com a participação dos chanceleres argentino, brasileiro e uruguaio, com o objetivo de analisar estas situações ocorridas durante o transcurso do ano. Da mesma forma, ainda em novembro, houve a realização da Sessão Extraordinária da Organização dos Estados Americanos, com vistas à decisão britânica, na qual o Brasil procurou ressaltar o papel de moderador na questão, apelando para a criação de um clima de confiança na resolução do litígio.

\footnotetext{
14 É interessante inferir aqui a lembrança da já citada Usina de Itaipu, outrora motivo de controvérsias sobre a sua posição estratégica para com o território argentino.

151988.

16 Na redação oficial do Ministério das Relações Exteriores, em seu relatório, a reunião descrita a seguir foi mencionada na seção concernente aos assuntos de âmbito bilateral. Tal fato evoca a prioridade com que é visto 0 parceiro argentino, não obstante a participação uruguaia. 0 Brasil, em sua linguagem oficial mais uma vez se colocava simbolicamente ao lado da solidariedade latino-americana, relatando a zona de conservação de pesca como zona de exclusão.
} 
Com relação ao Uruguai, salienta-se que são assinados acordos ${ }^{17}$, em agosto de 1986, quando da visita do então presidente Julio Sanguinetti a Brasília, à semelhança dos firmados com a Argentina Este posicionamento se dá através da Ata de Cooperação Econômica Brasil-Uruguai. O Ministério das Relações Exteriores (1988) descreve esta visita como uma retribuição da visita de Sarney ao Uruguai, a sua primeira como chefe de estado e de governo. Os acordos assinados previam a possibilidade do comércio livre de mais de mil produtos, na fronteira entre os dois países, sendo estes, provenientes da área primária, em especial. Ao lado disso, colocar-se-ia a estimulação da ampliação e diversificação das trocas bilaterais, através de produtos não tradicionais como os do setor automobilístico, bem como a prestação de serviços. Assim, incentivar-se-ia a reativação da economia uruguaia, com a expansão de produtos negociados e a possibilidade de investimentos em conjunto.

Danese (1999) lembra que o ano de 1986 é o ano que o presidente uruguaio passa a participar ativamente das reuniões encabeçadas pelo colega brasileiro e argentino. Esta é ainda, segundo o Itamaraty, a época de realizações das reuniões de subcomissões para desenvolvimento conjuntos das regiões fronteiriças, como parte de uma política para a integração de regiões limítrofes ${ }^{18}$.

Já, no ano seguinte, o Uruguai reiterara a posição de se juntar cada vez mais ao processo de integração. Registra-se, pelo Ministério das Relações Exteriores, em 1987, intenso processo de diálogo entre as autoridades executivas,

\footnotetext{
17 Registra-se o Protocolo de Expansão Comercial (PEC) e o Acordo de Alcance Parcial $n^{\circ} 35$, que propunham a diversificação do intercâmbio bilateral, como instrumentos de expansão de produtos negociados e de ampliação tarifária no que tange às preferências recíprocas.

18 Os dados trazidos pelo Ministério das Relações Exteriores (1988), referem-se à II Reunião da Subcomissão para 0 Desenvolvimento Conjunto de Zonas Fronteiriças, reunida entre 26 e 27 de julho de 1986. Também foi reavaliado para posterior execução o Projeto Jaguarão, dentro da Comissão Mista para o Desenvolvimento da Bacia da Lagoa Mirim, com a possibilidade das barragens de Talavera e Passo do Centurião.
} 
sendo que, em maio deste ano, Sarney é convidado a participar de uma reunião de trabalho com os colegas argentino e brasileiro na capital uruguaia.

No âmbito do Programa de Integração e Cooperação Econômica, foi realizada por ocasião da visita de José Sarney à Argentina, em julho de 1987, a assinatura de protocolos relativos à Cultura, Administração Pública e Moeda Comum $^{19}$. A visita do presidente brasileiro ao Centro Atômico de Pilcaneyéu é salientada como marco histórico na área da política nuclear, por expressar a confiança mútua entre os dois países. Tratava-se de instalações nucleares secretas. Galvão Flores (2005) relata que os jornais argentinos, como O Clarín, celebraram a visita, como a primeira vez que um chefe de estado tinha acesso a uma usina de enriquecimento de urânio a convite de outro. A partir daí, a abertura recíproca de programas nucleares assume caráter dado por definitivo, segundo a autora.

Em 06 de abril de 1988, pela Ata do Alvorada, é formalizada oficialmente a vontade uruguaia de aderir a um projeto de integração com os dois vizinhos. Este documento, chamado de Decisão Tripartite $n^{\circ} 1$, previa o esforço das três nações para a integração, elegendo os transportes terrestres como o melhor setor para o processo integrativo.

Fato importante cabe ser registrado, do ponto de vista institucional. Em 05 de outubro de 1988 é promulgada a nova Constituição Federal da República Federativa do Brasil, afirmado que o Estado buscará a integração econômica, política, social e cultural dos povos da América Latina, visando à formação de uma comunidade latino-americana de nações.

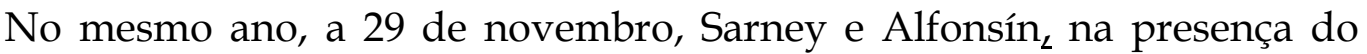
presidente uruguaio Julio Sanguinetti, assinam em Buenos Aires o Tratado de

${ }^{19}$ Esta receberia o nome de "gaúcho" e permitiria o comércio bilateral sem a necessidade do uso do dólar norteamericano. 
$64 \mid$ InterAção

Integração, Cooperação Econômica e Desenvolvimento Brasil-Argentina. Sinalizava o mesmo a implementação de um Mercado Comum entre os dois países em um prazo de dez anos. Pereira (2003) explica que o Uruguai manifestaria a sua adesão ao tratado, tão logo iniciasse mudanças internas que adaptariam o país às decisões já firmadas, desde 1985, por argentinos e brasileiros e da quais resultaram em vinte e três protocolos até então.

A possibilidade de eleições livres, por voto direto e secreto, evidenciou em 1989, o desgaste dos governos civis mais importantes do Cone Sul. Fato este comprovado pela eleição de Carlos Menem, ex-governador da Província de La Rioja, na Argentina, pelo setor mais liberal do Partido Justicialista (peronista), de oposição à União Cívica Radical, de Alfonsín. Todavia, este fato não interrompe o processo integrativo. Pouco mais de um mês após a sua posse, Menem se encontra com Sarney e Sanguinetti na cidade de Uruguaiana, no Rio Grande do Sul (agosto de 1989). Em novembro do mesmo ano, seria eleito por voto direto o brasileiro Fernando Collor de Mello, que se tornara oposicionista a Sarney e membro de um partido pequeno ${ }^{20}$, todavia com discurso que se considerava renovador das concepções estatais.

Estas questões servem, ao lado da exposição histórica até então feita, para um balanço do governo de José Sarney. Este governo vivera perspectiva a etapa considerada por Saba (2002) como a fase pragmática do integracionismo latinoamericano, a fase em que se abria a percepção de que o isolamento entre os Estados implicava em uma má resolução dos problemas enfrentados econômica e politicamente. Da mesma forma, não se podia tentar um processo que englobasse um empreendimento ambicioso, que congregasse a todos os países latino-americanos em um esquema único de integração, por exemplo.

\footnotetext{
${ }^{20}$ Após anos de militância na ARENA e posteriormente o PDS, Collor passou pelo PMDB, para em seguida passar à oposição no recém fundado e até então inexpressivo Partido da Reconstrução Nacional, o PRN, com o qual defendeu um discurso considerado neoliberal e preconizador da reforma do estado.
} 
65 InterAção

Quanto à integração, como ideia esboçada na estratégia de superação dos problemas enfrentados pelo Estado brasileiro, resta uma última análise da conjuntura vivida, na qual o enfraquecimento do multilateralismo no âmbito das negociações internacionais, por parte dos Estados mais ricos e suas organizações, permeou o período de governo estudado.

Como exemplo do primeiro item de agenda de problemas a serem enfrentados, vê-se a questão da negociação da dívida externa que associada à inflação excessiva corroía a popularidade do governo brasileiro. A necessidade de apoio econômico de potências exteriores se revestiu da má vontade, dado os fracassos do Plano Cruzado e de demais planos econômicos subsequentes. As relações com banqueiros credores e com o Fundo Monetário Internacional (FMI) também pioraram devido à moratória do pagamento dos juros da dívida externa no período do Ministro da Fazenda, Dílson Funaro. Esta medida foi tomada em 20 de fevereiro de 1987 e suspensa em dezembro do mesmo ano.

O apoio à tecnologia e à indústria, com viés de um Estado dirigente e desenvolvimentista pode ser visto na política para incremento da informática. Foi causado dissenso entre o Brasil e as potências capitalistas, em especial com os Estados Unidos, pela reserva de mercado para os computadores brasileiros. A ideia gozava de apoio interno, mas foi amplamente questionada pelos Estados Unidos da América em diversas oportunidades.

Somaram-se a este problema a questão da não assinatura do Brasil ao Tratado de Não-Proliferação Nuclear (TNP). Não obstante à distensão da corrida nuclear com os argentinos, a ascensão brasileira na matéria não era bem vista pelos países capitalistas centrais, em especial os Estados Unidos. O Brasil conquistara em 1987 o domínio total do processo de enriquecimento de urânio, como anunciado pelo presidente da Comissão Nacional de Energia Nuclear, Rex Nazaré. Pereira (2003) lembra ainda como dado importante, a visita de Richard 
66 InterAção

Kennedy, embaixador do Departamento de Estado dos Estados Unidos em março de 1988. Ante a negativa brasileira em assinar o tratado, explicou que existia a opção norte-americana em não pressionar o Brasil no tocante à assinatura. Entretanto, complementou dizendo que a lei de restrições estadunidense seria aplicada no que tange exportação de materiais e equipamentos nucleares ao Brasil.

Com a situação esmiuçada, ainda que brevemente, pode-se sintetizar que o momento vivido pelo Estado brasileiro era delicado do ponto de vista econômico. Tinha peculiaridades negativas, como as citadas oposições à política nuclear e à informática, dificultando o plano do diálogo com as potências centrais da economia mundial. Situação similar era vivenciada pelos Estados vizinhos, que também vivenciavam a abertura democrática. Isso ensejava uma visão mais distendida no signo da solidariedade entre os sul-americanos e veio a favorecer o que viria a ser chamado de momento pragmático de integração regional.

Não se pode perder de vista o momento histórico. Estas tensões com o "centro" citadas acima, favoreceram da mesma forma as tentativas de reparação pautadas no plano interno. Neste aparece uma visão favorável a reformas e ajustes estatais. No plano externo coadunariam com desenhos de integração mais ambiciosos como os que seriam traçados por Collor e Menem. Se ainda não se podia falar em reforma do Estado no governo de José Sarney, a construção do Mercosul se insere neste período histórico, ainda que desenvolvida, de outra forma, nos governos posteriores.

Anos depois, Sarney fez uma reflexão a respeito do que seu governo projetara como ideia de integração, criticando os sucessores

[...] a Ata de Iguaçu foi um primeiro passo na criação de um mercado comum. Não era a zona de livre-comércio, mas a criação de um mercado comum. Nosso modelo era o europeu e dele derivava. Um modelo no qual as coisas não se restringissem 
à área econômica. Estabelecemos um prazo de dez anos, com integração por setores, stepbystep, para não haver retrocesso. [...] Certamente me perguntarão: “Onde o projeto fracassou?” Talvez tenha fracassado no que se refere a uma posição demagógica, quando Menem e Collor, então presidente do Brasil, resolveram implantar a tarifa zero e transformar o mercado comum numa zona de livre-comércio, cujos objetivos se esgotavam numa união aduaneira (SARNEY, 2003, p.178).

Levando em consideração a hipótese traçada na introdução do trabalho, defende-se aqui, com o fim do governo Sarney, o término de um paradigma desenvolvimentista na condução da integração. Isto porque findava o modelo de desenvolvimento da industrialização via a substituição de importações, que havia pautado a política brasileira lato sensu ao longo da segunda metade do século $X X$, quando houve a prevalência de uma preocupação de caráter mais nacionalista e defensora da soberania estatal.

Como mudança da política externa brasileira dos anos 80 , surge o país com o perfil de potência média, tal qual expresso por Sennes (2003). Países como o Brasil tendem então, a atuar em fóruns internacionais e multilaterais sem, contudo, pretenderem ficar atrelados à influência direta das grandes potências. No plano regional, as potências médias tendem a reproduzir o papel de influência e presença bem marcadas, tal como as grandes potências executam em nível global.

Reis da Silva (2009), ao analisar as rupturas e continuidades com este paradigma desenvolvimentista, percebe que, na década de 1990, surge uma nova orientação da política externa. Através da ação da diplomacia, procurou-se construir inovação também na imagem do Brasil. O país passa a se creditar como líder regional, buscando aproximação com os países desenvolvidos e inserção na ordem global. A vulnerabilidade externa, de que o país era vítima, seria minimizada por estas estratégias. É importante, também, salientar que, nesta 
época, o Brasil passa a demonstrar interesse em ocupar uma vaga no Conselho de Segurança da Organização das Nações Unidas.

\section{GOVERNO COLLOR}

Eleito pelo jovem Partido da Reconstrução Nacional (PRN), Fernando Collor assume o país com uma inflação galopante e com o discurso de modernização do Estado. Combinado com medidas impopulares, os seus planos econômicos que fracassam. Seu primeiro Ministro das Relações Exteriores será o jurista mineiro Francisco Rezek. O início das reformas regulatórias, no Governo Collor, ocorre no mesmo momento em que no plano histórico mundial se assiste à dissolução da União Soviética e à supremacia das ideias políticas e econômicas liberais do polo ocidental.

Neste novo cenário internacional o gradual sucesso do projeto da União Europeia (UE), o surgimento de um processo de globalização lastrado na ampliação do poder das grandes empresas mundiais hegemonização da ideologia neoliberal e da diplomacia econômica internacional, juntamente com a emergência do novo quadro político sul-americano pós-regimes militares e com a consolidação dos processos de democratização, viabilizaram um projeto regional e possibilitaram $\mathrm{O}$ amadurecimento do movimento de aproximação e cooperação entre os dois países -chave da região: Brasil e Argentina (GUEDES DE OLIVEIRA, 2001, p.22).

No ínterim das reformas, surge a nova proposta de integração regional. Não se pode olvidar que a mesma ocupa também um papel prático na liberalização dos mercados e da economia ${ }^{21}$.

\footnotetext{
${ }^{21}$ Jaguaribe (2005) expressa que nas condições atuais, mesmo um novo desenho para um novo modelo nacional desenvolvimentista, passa por uma questão de integração regional, sem olvidar da necessidade da cooperação e do livre-comércio.
} 
A América Latina, entretanto, mesmo com a mudança de governo, não deixava de ser lembrada desde o primeiro momento. Dizia Collor em seu discurso de posse

\begin{abstract}
A tradição de amizade, de esforço em relação à paz regional, de cooperação e diálogo serão reforçadas. Daí a acrescente importância do processo de integração latino-americana, que pretendo aprofundar sistematicamente em meu governo. Penso que a integração é passo obrigatório para a modernização de nossas economias e, portanto, condição para que a América Latina possa juntar-se aos protagonistas deste momento de mudança no cenário mundial. A integração latino-americana vai deixando de ser um sonho para ser uma realidade tão concreta quanto fecunda. O desenvolvimento econômico e social de toda a região há de aproximar ainda mais nossos povos irmãos fortalecendo o regime democrático por eles escolhido (COLLOR DE MELLO apud AZAMBUJA p.65).
\end{abstract}

A percepção que seria conduzida pelo Estado Brasileiro, durante esta época, podem ser percebidas, como explana Azambuja (1990), nos termos de entendimento de que existiam diferenças de desenvolvimento e dimensão econômica entre os países que compunham a ALADI e que enfocavam a América Latina como um todo. Para tanto, partia-se da análise de que a década de 1980 fora para a referida região uma "década perdida" 22 do ponto de vista econômico. Os projetos de integração deveriam então contemplar a abertura das economias, marcadas por um contexto de competitividade, partindo de nova racionalidade e orientada por princípios de maior eficiência. Haveria então, um aprimoramento, uma modernização dos parques produtivos nacionais, com abertura setorial e seletiva. Aproveitar-se-ia a flexibilização jurídica dada pelo Tratado de Montevidéu de 1980, que implicaria em reflexos institucionais compatíveis com a realidade almejada.

\footnotetext{
22 Esta menção é por várias vezes tomada também pelo presidente Collor, como registra o Ministério das Relações Exteriores (1990) por ocasião do discurso de Collor ao Congresso Argentino em sua primeira visita àquela nação, em 06 de julho de 1990 e por ocasião do Tratado de Assunção de 1991.
} 
70 InterAção

Era necessário, na implementação deste projeto, que se realizasse um chamamento ao empresariado, estabelecendo áreas prioritárias de ação, seja por iniciativas bilaterais ou por grupos de países com potencial para o desenvolvimento de projetos de infraestrutura, energia, transportes e comunicações entre eles.

Aqui emergem os signos liberais da eficiência e da concorrência, tomada como competição a ser tratada no plano externo, em uma lógica de abertura econômica, o que redundaria em uma necessidade de ajuste do Estado. O Itamaraty passa a ressaltar em suas publicações, aspectos que eram levados a execução e que denotam este viés político. Como pontos tocantes do início do governo, alguns são registrados como relevantes para a integração BrasilArgentina.

O Ministério das Relações Exteriores (1990) anotou que a primeira visita de Collor ao exterior, como presidente, foi à Argentina. Como marco histórico desta visita, é assinada a Ata de Buenos Aires, em 06 de julho de 1990, que previa o estabelecimento de um mercado comum entre os dois países até 31 de dezembro de 1994. A estrutura orgânico-funcional do acordo previa a existência de um grupo técnico-político, o Grupo de Trabalho Binacional para a conformação do Mercado Comum, formado por Chanceleres, Ministros da Economia ${ }^{23}$ e Presidentes dos Bancos Centrais de ambos os países. Denominado nos textos oficiais de Grupo Mercado Comum, seria subordinado à Comissão de Execução do Tratado de Integração, Cooperação e Desenvolvimento celebrado ainda nos Governos Sarney-Alfonsín.

Nessa mesma data, era celebrado em Buenos Aires o Tratado para o Estabelecimento de um Estatuto para as Empresas Binacionais Brasileiro-

${ }^{23} 0$ Ministério da Fazenda fora extinto por Collor, que criou em seu lugar um único ministério para a área econômica, englobando também o Ministério do Planejamento. 
71 InterAção

Argentinas. Fora lançada nota à imprensa, ainda antes da visita, salientando que o edital da construção da licitação da Ponte Rodoferroviária sobre o rio Uruguai, ligando pelo lado brasileiro a cidade de São Borja à vizinha argentina de Santo Tomé, seria feito em regime de concessão, portanto sem ônus estatal. O comunicado oficial, assinado pelos dois presidentes, dava conta de que este passo era decisão comum de fundar a integração em obras concretas. ${ }^{24}$

Nesse mesmo comunicado conjunto, ainda traz o Ministério das Relações Exteriores, a constituição e instalação da Comissão Parlamentar estabelecida no Tratado de Integração, Cooperação e Desenvolvimento, estendendo ao âmbito dos Poderes Legislativos, a possibilidade de participar do processo de integração, em caráter consultivo. Contaria com doze legisladores de cada país com mandato de dois anos. São salientados ainda como questões de cooperação: a) a integração da indústria automobilística; b) a cooperação nuclear para fins pacíficos; c) a preocupação com o meio ambiente, em especial de coordenação de trabalhos para a então futura ECO 9225; d) o apoio à cooperação bilateral sobre a Antártida; e) o combate ao narcotráfico; f) no âmbito da Bacia do Prata, apoio à construção da Hidrovia Paraguai-Paraná. Enaltecia-se, também o Acordo de Previdência Social e fazia-se uma previsão de estudo da chamada "Iniciativa para as Américas" lançada em 27 de junho de 1990 pelo presidente dos Estados Unidos, George Bush26.

\footnotetext{
${ }^{24}$ Repetem-se situações similares no universo da linguagem. Novamente se faz a integração, simbolicamente do gesto político com a construção de pontes. Desta vez com chamamento à iniciativa privada.

${ }^{25}$ Refere-se à Conferência das Nações Unidas sobre o Meio Ambiente que viria a ser realizada no Brasil em 1992. Esta conferência mostrava mais um ponto de inserção do Brasil, avocando a si responsabilidade com o tema da proteção ao meio ambiente que ganhara espaço na agenda internacional.

${ }^{26}$ Refere-se ao Governo de George H. Bush (1989-1993). A Iniciativa, para as Américas, construía a posição estadunidense no pós-Guerra Fria, para o Continente Americano. Revelava-se, assim, uma tentativa de manutenção de influência sobre a área considerada aliada tradicional e que se sustentava por três pilares principais: Criação de uma zona hemisférica de livre comércio, negociação para a redução da divida externa da região e uma proposta para 0 aumento dos investimentos na América Latina e no Caribe. Esta área seria posteriormente planejada com o nome de Área de Livre-Comércio das Américas (ALCA).
} 
72 InterAção

Nova linha de discurso liberalizante viria em 12 de julho de 1990, como registra o Ministério das Relações Exteriores (1990). Os presidentes de Brasil e Argentina se alinhavam através de nota conjunta, aos projetos de eliminação de subsídios da agricultura como condição indispensável para a liberalização do comércio internacional, ao apoiarem em conjunto, a Declaração de Houston, emitida ao final da Reunião do Grupo dos 727, na cidade estadunidense de mesmo nome. Nela se fortalecia a visão liberal que deveria prevalecer na Rodada Uruguai do GATT. 28

Entre 03 e 04 de setembro de 1990, ocorria a primeira reunião do Grupo de Mercado Comum Brasil-Argentina, na qual seria afirmada a necessidade no menor prazo possível da coordenação e harmonização das políticas macroeconômicas entre os sócios. Constituía-se a feitura de grupos técnicos de assessoramento de trabalho do órgão e previa-se a reunião de todos os acordos comerciais existentes em um Acordo de Complementação Econômica. Uma vez instituído, este acordo passaria a aplicar uma margem de preferência mínima de $40 \%$ à totalidade de produtos regulados num prazo de dois meses. Havia a possibilidade de exceções, que não chegariam a 20\% dos mesmos, bem como uma possibilidade de salvaguarda. Por fim, previa a necessidade de definição um cronograma de redução de tarifas: automático, linear e semestral, prevendo alcançar uma tarifa zero em dezembro de 1994.

Outrossim, no que tange à política nuclear, ocorre a Declaração sobre política Nuclear Comum de 28 de novembro de 1990, revelando a posição argentino-brasileira quanto à energia nuclear, num contexto de superação da

\footnotetext{
27 Grupo que reunia na época os países mais ricos e industrializados do mundo, Alemanha, Canadá, Estados Unidos, França, Grã-Bretanha, Itália e Japão. A partir de 1997, foi oficializado o convite à Rússia, na Cúpula realizada em Denver nos Estados Unidos. 0 grupo passaria então a se chamar G8.

28 Há de se notar a proximidade do discurso que, não obstante assumir a defesa de países mais distantes do centro da economia mundial, adotava aqui uma postura liberal ao celebrar a não-interferência econômica dos Estados no mercado, através de subsídios.
} 
73 InterAção

Guerra Fria e de afirmação da consolidação da paz na Europa. A Resenha de Política Exterior do Brasil, revela o discurso oficial de Collor em Foz do Iguaçu

A Declaração que acabamos de firmar merece, como poucas, ser qualificada de histórica. Inicia uma nova fase nas relações bilaterais no domínio nuclear, abre negociações conjuntas com a Agência Internacional para a Energia Atômica e aponta para a implementação plena do Tratado de Tlatelolco. [...] Com este documento damos o passo conclusivo para a completa superação de qualquer veleidade de competição entre nossos países no campo nuclear. Ele vem coroar o processo que começou com a Declaração conjunta sobre a política nuclear de 1985, firmada nesta mesma cidade (COLLOR DE MELLO, 1990, p.41).

Ainda digno de nota em 1990, vê-se no âmbito bilateral o protocolo de $\mathrm{n}^{\mathrm{o}}$ 12 da Ata de Integração Econômica Brasil-Argentina. Seria lançado o protótipo de um avião, o CBA 123, que era oriundo de um projeto de construção de aeronaves feitas em conjunto pelos dois países. ${ }^{29}$ Além disso, no plano da infraestrutura ${ }^{30}$, é celebrado acordo de liberalização e facilitação do transporte de carga e sobre transporte rodoviário.

A aceleração do processo de integração se dá em 1991, com a assinatura de um Tratado para a Constituição do Mercado Comum do Sul, que passaria a ser chamado de Mercosul. Reunidos em 26 de março, os presidentes da Argentina e Brasil, somavam-se ao presidente uruguaio, Luis Alberto Lacalle Herrera e ao paraguaio Andrés Rodriguez ${ }^{31}$, para a celebração deste marco institucional na cidade de Assunção, capital do Paraguai. O discurso de Collor, cuja transcrição embora longa, será recortada nos trechos considerados mais elucidativos,

\footnotetext{
${ }^{29}$ Para tanto houve a presença do então chanceler Domingo Cavallo em São José dos Campos, estado de São Paulo.

30 É interessante notar que o governo Collor, enxugou o número de ministérios a exemplo da economia, colocando a infraestrutura (transportes, minas e energia e comunicações) em uma única pasta.

${ }^{31}$ Rodriguez substituíra ao ditador Alfredo Stroessner e fora confirmado no cargo via eleição. Defendia ele também pressupostos liberais na economia.
} 
74 InterAção

enfocará novamente a orientação e os signos presentes no espírito do tempo que como se disse, passara a nortear o Estado brasileiro de então.

Este encontro que hoje celebramos constitui marco de indiscutível significado na história de nossos quarto países e da América Latina. [...] Ao concluirmos este Tratado, reafirmamos a inabalável vontade política dos Governos da Argentina, do Paraguai, do Uruguai e do Brasil de somar esforços na tarefa solidária de construção de sociedades mais prósperas, mais justas e convictamente comprometidas com as liberdades essenciais e o regime democrático, sociedades atentas sempre à necessidade do desenvolvimento em harmonia com o meio ambiente. [...] São bases sólidas, a nos ampararem solidariamente na busca de respostas comuns e efetivas aos desafios que se assomam no horizonte da ordem econômica internacional. Nossos Governos vêm enfrentando com galhardia esses desafios. Temos empreendido reformas internas corajosas de redefinição do papel do Estado, de aperfeiçoamento das instituições democráticas, de resgate da capacidade produtiva, de estímulo às forças de mercado, de abertura ao exterior, de modernização econômica, com ênfase particular à melhoria crescente do nível de vida de nossos povos (COLLOR DE MELLO, 1991, p.31, grifo nosso).

Completava Collor, ainda em seu discurso, total apoio às iniciativas integracionistas amparadas no Tratado de Montevidéu de 1980, o referido constituinte da ALADI, afirmando que o Mercosul não constituiria uma área econômica excludente, mas sim seria um espaço econômico acessível e complementar dentro do espírito de cooperação e intercâmbio de grupos e países latino-americanos. Era a possibilidade de complementações da economia, uma opção da modernidade, segundo o presidente. Enfocava que o mundo passava por um agigantamento do processo de transnacionalização das relações internacionais o que implicava em dificuldades a serem transpostas.

Sabíamos que numa conjuntura internacional em tantos capítulos adversa, á conta do ressurgimento extemporâneo de barreiras comerciais, práticas protecionistas e medidas discriminatórias no sentido Norte-Sul, a alternativa mais recomendável era a viabilização do que, aqui, na capital paraguaia, estamos concretizando, para a surpresa dos 
75 InterAção

pessimistas, mas para a grandeza e a prosperidade dos nossos países (COLLOR DE MELLO, 1991, p.32).

Sintetizando a postura perante as iniciativas tomadas pela ALADI, é válido transcrever o trecho relativo da nota distribuída à imprensa, na mesma data

O Tratado é aberto à adesão, mediante negociação, de todo país membro da Associação Latino-americano de Integração (ALADI), desde a data de sua entrada em vigor. No entanto, por força de incompatibilidade técnica (por exemplo, na definição de uma tarifa externa comum), os membros da ALADI que participarem de associações extra-regionais ou outros esquemas de integração sub-regional somente poderão aderir cinco anos após essa data (BRASIL, 1991, p.280).

Com relação aos demais membros signatários do Tratado de Assunção de 1991, Paraguai e Uruguai32, vale lembrar a dimensão que a sua aderência significou a possibilidade de evitar a disputa histórica dos maiores Estados do Cone Sul, Brasil e Argentina, em buscar em separado, aliados de ocasião para opções individualistas. Por outro lado, a possibilidade do aumento de participantes poderia significar incremento ao bloco.

O que poderia ser considerado como um grande ausente no tratado, o Chile, viria a se tornar Estado associado ao grupo em momentos posteriores. $\mathrm{Na}$ realidade, como lembra Canani (2004), o Chile possuía tarifas médias inferiores aos que viriam a ser os demais Estados parceiros. Isso o impediria a adesão ao bloco, pelo menos num primeiro momento. A construção de uma parceria com os países mercosulinos viria já na negociação relativa à Iniciativa para as

\footnotetext{
320 Uruguai, em fato digno de nota segundo o Ministério das Relações Exteriores (1991) viria a assinar com o Brasil, às vésperas do Tratado de Assunção, o convênio de abastecimento do trigo, o que poderia ser visto como similar trigo argentino. Igualmente, seria celebrada com o Brasil a Ata de Instalação do Comitê de Fronteiras entre a cidade uruguaia de Artigas e a cidade brasileira de Quarai, ainda em 1991, tal como menciona a Resenha de política Exterior de 1991.
} 
76 InterAção

Américas, quando em junho de 1991 se propõe o formato 4+1 (o Chile e mais os quatro membros do bloco).

No âmbito do Tratado de Assunção, é realizada para dirimir as diferenças entre os membros do Grupo, a celebração do Protocolo de Brasília para a Solução de Controvérsias entre os Estados-membros, além de outros aspectos institucionais importantes, como o Regimento Interno do Grupo Mercado Comum, disposições acerca de certificados de origem e acordos de complementaridade setorial. Disso também redundou a elaboração de um estudo encaminhado pelos presidentes, para o estabelecimento de contatos no âmbito da ALADI, que tornasse possível a vinculação do Mercosul com outros grupos econômicos e países latino-americanos.

Fato é que ante a perspectiva Mercosul, puderam se desenhar frentes de negociação, como por exemplo, o tratado dos países mercosulinos ${ }^{33}$ com os Estados Unidos da América, relativo a um Conselho de Comércio e Investimentos ainda de 1991, o chamado Acordo do Jardim das Rosas, em que os norte-americanos, pela primeira vez, negociariam com um órgão multilateral latino-americano. Também foi assinalada a importância do Banco Interamericano de Desenvolvimento na concretização do processo de integração.

Ocorre antes do término precoce do governo de Collor de Mello, a mudança de titular na chancelaria brasileira, com um novo ministro, Celso Lafer. Da esteira das preocupações de Collor, o chanceler propugna a visão de uma inserção competitiva do país, uma resposta para as mazelas da falta de desenvolvimento, da necessidade de modernização em uma sociedade que se globalizava. A inserção competitiva era, segundo Lafer (1992), a palavra síntese da política externa vivenciada. Assim, passava por uma dinâmica no plano

\footnotetext{
${ }^{33}$ Celebrado de forma multilateral, entre os quatro Estados e uma vez que o MERCOSUL ainda não possuía uma personalidade jurídica internacional, que só viria com o Protocolo de Ouro Preto de 1994.
} 
77 InterAção

interno na qual seria necessária a liberalização da economia, a reforma do Estado, o controle orçamentário, a desregulamentação, privatizações e abertura econômica. Somava-se a estes itens a promoção da educação básica e do desenvolvimento científico e tecnológico.

A Declaração de Las Leñas, de junho de 1992, reitera a intenção da construção de um Mercado Comum estabelecendo um cronograma para a feitura do mesmo até 1994, tal qual previa o Tratado de Assunção, bem como estabelece medidas adicionais. Nessa oportunidade, salienta Barbosa (2010), foi celebrado protocolo de cooperação e assistência judiciária em matéria civil, comercial, trabalhista e administrativa. Da mesma forma, foi estabelecido procedimento para reclamações quanto a práticas desleais de comércio, adoção de critérios comuns para as negociações com demais membros da ALADI e ainda um plano de educação trienal.

As denúncias de corrupção no governo Collor, levaram à instauração do processo de impeachment do Presidente da República, ao seu afastamento e, finalmente, à sua renúncia quando do seu julgamento pelo Senado brasileiro. Em fins de dezembro de 1992, assume a titularidade da presidência, o então vicepresidente Itamar Franco. Este que seria um governo de transição acaba por participar de momentos importantes, do ponto de vista histórico-institucional, dos projetos de integração que vinham sendo traçados. Seu primeiro Ministro das Relações Exteriores, Fernando Henrique Cardoso, viria a ser o condutor do plano de estabilização da economia, o Plano Real e alçado à candidatura presidencial com sucesso em 1994. O legado de Collor, conclui-se na gênese de um paradigma dito neoliberal na política externa, levado adiante, com singularidades temporais, por Fernando Henrique.

O neoliberalismo apesar de se estabelecer, segundo a literatura especializada, como este norteador de um novo paradigma, guarda alguma 
78 InterAção

conexão com pensamentos associativistas da Política Externa Independente. Neste caso, o associativismo aproximava-se dos Estados Unidos. Porém, no caso do paradigma da política externa dita neoliberal, a aproximação se dará não apenas com este país ou com os demais países ricos, sobretudo, com as instituições e o sistema econômico e político defendido no pós- Guerra Fria.

Em ambas as correntes, todavia, a ideia da cooperação internacional ia sair fortalecida, via a criação de instituições internacionais. Esta seria a viga mestra do pensamento brasileiro sobre as relações internacionais, durante a citada década de 1990. Pensa-se, aqui, no ponto de equilíbrio para o desenvolvimento, que como já salientado, é um vetor importante da política externa do Brasil. Assim, os processos de integração apareceriam não como fins, mas como meios para se chegar ao mesmo.

Por outro lado, o neoliberalismo produziria o rompimento com a visão de centro e periferia, substituídos pelo conserto da globalização, através da unificação proposta pelas estruturas transnacionais do capitalismo. Esta adequação acabaria por fazer superar a instabilidade econômica, acabando com a inflação. Contudo, não deixou de ser alvo de críticas, quanto à efetiva concretização de políticas de bem-estar social no Brasil e na América Latina.

\section{CONSIDERAÇÕES FINAIS}

Na esteira da tradição desenvolvimentista, o Estado avoca a si o papel de condutor do processo de integração, a partir do governo José Sarney. Nesse caso, de um processo de integração ainda pautado para dar respostas a mazelas principalmente nacionais, em um contexto de crise econômica e de dificuldades de diálogo com Estados mais desenvolvidos economicamente. Opta-se por uma 
79 InterAção

integração a passos lentos, na visão de seus fundadores. O Mercosul viria ulteriormente acelerar este processo. Ainda houvesse organizações voltadas para a integração a América Latina, como a ALADI e a Comunidade Andina, o Mercosul constitui algo novo, pela possibilidade teleológica de assemelhar-se à experiências europeias em um curto espaço de termo, como afirmava o seu Tratado constituinte.

Tal fato, embora não se revele possível de concretização, é importante dado o desejo expressado pelos seus criadores de superar divisões existentes desde a formação dos Estados - Nacionais do Cone Sul. Contudo, vê-se que a retórica afirmada pelos motores da integração, Brasil e Argentina, encaixa-se, em um primeiro momento, na busca pela inserção na economia e na política da globalização da década de 1990. Esta, de viés neoliberal, ou seja, de rompimento com a dita tradição de desenvolvimento planejado pelo Estado, propõe maior participação política na esfera global, aceitando instituições e tentando interferir nas suas constituições e objetivos.

No Brasil, foco deste trabalho, vê-se que a situação sofre clivagens ao longo do tempo. Com Collor, há um período mais radical no que tange ao desmonte do Estado e política externa anterior. Aqui a preocupação com a histórica autonomia e, consequente, manutenção de uma hegemonia não declarada, é relativizada para dar uma resposta a desafios extra regionais. Assim, a integração regional é partícipe deste jogo liberalizante, condizente com as reformas estatais a serem perseguidas. Conclui-se, analisando a quebra de paradigmas, que apesar de que o projeto de integração mais desenvolvida, o Mercosul, ainda não ter se concretizado ou ter falhado em suas finalidades, foi ele dado importante para o entendimento dos câmbios de perspectivas na política externa do momento abordado. 


\section{REFERÊNCIAS}

AYERBE, Luis Fernando. Neoliberalismo e Política Externa na América Latina: uma análise a partir da política argentina recente. São Paulo: UNESP, 1998.

AZAMBUJA, Marcos. Discurso pronunciado pelo Secretário Geral de Política Exterior, Marcos Azambuja, por ocasião da V Reunião do Conselho de Ministros das Relações Exteriores da ALADI, realizada no México em 30 de abril de 1990. In: BRASIL, Resenha de Política Exterior do Brasil. Número 65 15 a 31 de março a junho de 1990 ano 16. Brasília: Ministério das Relações Exteriores,1990.

BARBOSA, Rubens. O Mercosul e a Integração Regional. São Paulo: Fundação Memorial da América Latina: Imprensa Oficial do Estado de São Paulo, 2010.

BOBBIO, Norberto. Ciência Política. In: BOBBIO, Norberto; MATTEUCCI, Nicola e PASQUINO, Gianfranco (Org). Dicionário de Política. Brasília: UNB, 1998.

BRASIL . Ministério das Relações Exteriores, Relatório, 1985. Brasília: MRE/CDO, 1986.

Ministério das Relações Exteriores, Relatório, 1986. Brasília: MRE/CDO, 1988.

Ministério das Relações Exteriores, Relatório, 1987. Brasília: MRE/CDO, 1989.

Ministério das Relações Exteriores, Posições Brasileiras em Política

Externa, Repertório. Brasília: MRE/gabinete do Ministro/ Secretaria de Imprensa (mimeo), 1988.

.Declaração de Iguaçu Disponível

em:<http://www2.mre.gov.br/dai/b_argt_256_733.htm >. Acesso em: 12 jun. 2011.

.Resenha de Política Exterior do Brasil. Número 6515 a 31 de março a junho de 1990 ano 16. Brasília: Ministério das Relações Exteriores,1990.

Resenha de Política Exterior do Brasil. Número 66 julho a setembro de 1990 ano 16. Brasília: Ministério das Relações Exteriores,1990. 
$81 \mid$ InterAção

Resenha de Política Exterior do Brasil. Número 67 outubro a

dezembrode1990 ano 16. Brasília: Ministério das Relações Exteriores,1990.

Resenha de Política Exterior do Brasil. Número $681^{\circ}$ semestre de 1991

ano 17. Brasília: Ministério das Relações Exteriores, 1991.

Resenha de Política Exterior do Brasil. Número $701^{\circ}$ semestre de 1992 ano 18. Brasília: Ministério das Relações Exteriores, 1992.

Resenha de Política Exterior do Brasil. Número $712^{\circ}$ semestre de 1992 ano 18. Brasília: Ministério das Relações Exteriores, 1992.

Constituição da República Federativa do Brasil. Brasília: Senado Federal, 2007.

CANANI, Ney. Política externa no Governo Itamar Franco(1992-1994):

continuidade e renovação de pardigma nos anos 90. Porto Alegre: UFRGS, 2004.

COLLOR DE MELLO, Fernando. Discurso do Presidente Fernando Collor na cerimônia de assinatura da "Declaração sobre Política Nuclear Comum Brasileiro-Argentina”, realizada em Foz do Iguaçu em 28 de novembro de 1990. In: BRASIL, Resenha de Política Exterior do Brasil. Número 67 outubro, novembro e dezembro de 1990 ano 16. Brasília: Ministério das Relações Exteriores, 1990.

Discurso do Presidente Fernando Collor por ocasião da assinatura do Tratado para a Constituição do Mercado Comum do Sul (MERCOSUL), em Assunção, em 26 de março de 1991 In: BRASIL, Resenha de Política Exterior do Brasil. Número $681^{\circ}$ semestre de 1991 ano 17. Brasília: Ministério das Relações Exteriores, 1991.

DANESE, Sérgio. Diplomacia Presidencial. Rio de Janeiro: Topbooks, 1999.

GALVÃO FLORES, Maria Cândida. O Mercosul nos Discursos do Governo Brasileiro. Riode Janeiro: FGV, 2005.

GUEDES DE OLIVEIRA, Marcos Aurélio. MERCOSUL e Política. São Paulo: LTr, 2001.

HIRST, Monica. Transição Democrática e Política Externa: A Experiência Brasileira. In: Dados - Revista de Ciências Sociais. Vol.27, n³. Rio de Janeiro: Campus, 1984.

MONIZ BANDEIRA, Luiz Alberto. Brasil, Argentina e Estados Unidos Conflito e integração na América do Sul (Da Tríplice Aliança ao MERCOSUL 1870-2003). Rio de Janeiro: Revan, 2003. 
82 InterAção

PEREIRA, Analúcia Danilevicz. A política externa do Governo Sarney: a Nova República diante do reordenamento internacional. Porto Alegre: UFRGS, 2003.

REIS DA SILVA, André Luiz. Do Otimismo Liberal à Globalização Assimétrica: a política externa do Governo Fernando Henrique Cardoso (19952002). Curitiba: Juruá, 2009.

SABA, Sérgio. Comércio Internacional e Política Externa Brasileira. Porto Alegre: Livraria do Advogado, 2002.

SARNEY, José. José Sarney. In: MAGALHÃES, Fabio. Presidentes e o MERCOSUL: reflexões sobre a integração. São Paulo: Memorial da América Latina, 2003.

SENNES, Ricardo. As mudanças da política externa brasileira nos anos 80: uma potência média recém industrializada. Porto Alegre: UFRGS, 2003.

SILVA, Guilherme A.; Willians Gonçalves. Dicionário de Relações Internacionais. Barueri: Manole, 2005. 